\title{
REVIEW
}

\section{Acromioclavicular Joint Cyst Formation}

\author{
ANDREW D. HILLER, ${ }^{1}$ JOSHUA D. MILLER, $^{2}$ AND JOHN L. ZELLER ${ }^{3 *}$ \\ ${ }^{1}$ Division of Anatomical Sciences, University of Michigan Medical Center, \\ Ann Arbor, Michigan \\ ${ }^{2}$ Department of Orthopaedic Surgery, University of Michigan Medical Center, VA Medical Center, \\ Ann Arbor, Michigan \\ ${ }^{3}$ Division of Anatomical Sciences, Department of Medical Education, University of Michigan Medical Center, \\ Ann Arbor, Michigan
}

\begin{abstract}
Acromioclavicular joint $(A C J)$ cysts are an uncommon and unusual sequela associated with shoulder pathophysiology. The majority of literature on AC] cysts consists of individual case reports with no definitive literature review currently available. In addition to a comprehensive literature review, four clinical cases are presented in this report. First described by Craig (1984), a total of 41 cases have been previously reported in the literature. Of these cases, five occurred with the rotator cuff musculature intact. The remaining 36 cases of ACJ cysts occurred in patients with a complete tear/avulsion of the rotator cuff. Previous attempts at compiling a complete record of all reported cases have combined several distinct conditions into a single category. This article presents two distinct etiologies for the pathogenesis of $\mathrm{ACJ}$ cyst formation. In the presence of an intact rotator cuff, a Type 1 cyst can form superficially and be limited to the ACJ. Following a massive or traumatic tear of the rotator cuff, mechanical instability of the humeral head can cause a deterioration of the inferior acromioclavicular capsule (cuff tear arthropathy) and an overproduction of synovial fluid. Overtime, a "geyser" of fluid can form between the glenohumeral and the ACJ, forming a Type 2 cyst. This differentiation and categorization is essential for appropriate classification and treatment. Clin. Anat. 23:145-152, 2010. @ 2010 Wiley-Liss, Inc.
\end{abstract}

\section{Key words: ACJ cyst; geyser sign; rotator cuff tear; cuff tear arthropathy}

\section{INTRODUCTION}

Acromioclavicular joint $(A C J)$ cysts can develop in either the subcutaneous tissue superficial and limited to the $\mathrm{ACJ}$ or result from ongoing degenerative changes related to the glenohumeral $(\mathrm{GH})$ joint. First described by Craig (1984), in addition to the four clinical cases presented in this report, 41 cases (Fig. 1) have been previously reported in the literature (Burns and Zvirbulis, 1984; Craig, 1986; Rockwood and Burkhead, 1988; Rowe, 1988; Nardini, 1991; Groh et al., 1993; Postacchini et al., 1993; Lizaur Utrilla et al., 1995; Le Huec et al., 1996; Segmuller et al., 1997; Marino et al., 1998; Selvi et al., 1998; Cvitanic et al., 1999; Montet et al., 2004; Tshering et al., 2005; Moratalla and Gabarda, 2007; Kontakis et al., 2007; Mullett et al., 2007; Nowak et al., 2009). Initially, two cases of soft-tissue masses overlying the $\mathrm{ACJ}$ were excluded from classification. These cases were re-classified as Gout/DISH (Echols et al., 2000) and juxta-articular myxoma (DeSantis et al., 2001) (Fig. 1).

The exact etiology of the ACJ cyst has been a source of controversy. Accordingly, the research objective of this author is to define the degenerative stages giving rise to cyst development, to identify the varied anatomic etiologic factors and to provide treatment options based upon the underlying pathology. It is the position of this author that two distinct etiologies exist for the formation of an ACJ cyst (Fig. 2). The Type 1 cyst is isolated and limited to

\footnotetext{
*Correspondence to: John L. Zeller, Division of Anatomical Sciences, 3767 Medical Science II Building, 1135 E. Catherine St., Ann Arbor, Michigan, USA. E-mail: jlzeller@med.umich.edu
}

Received 25 August 2009; Revised 7 November 2009; Accepted 9 November 2009

Published online 12 January 2010 in Wiley InterScience (www. interscience.wiley.com). DOI 10.1002/ca.20918 


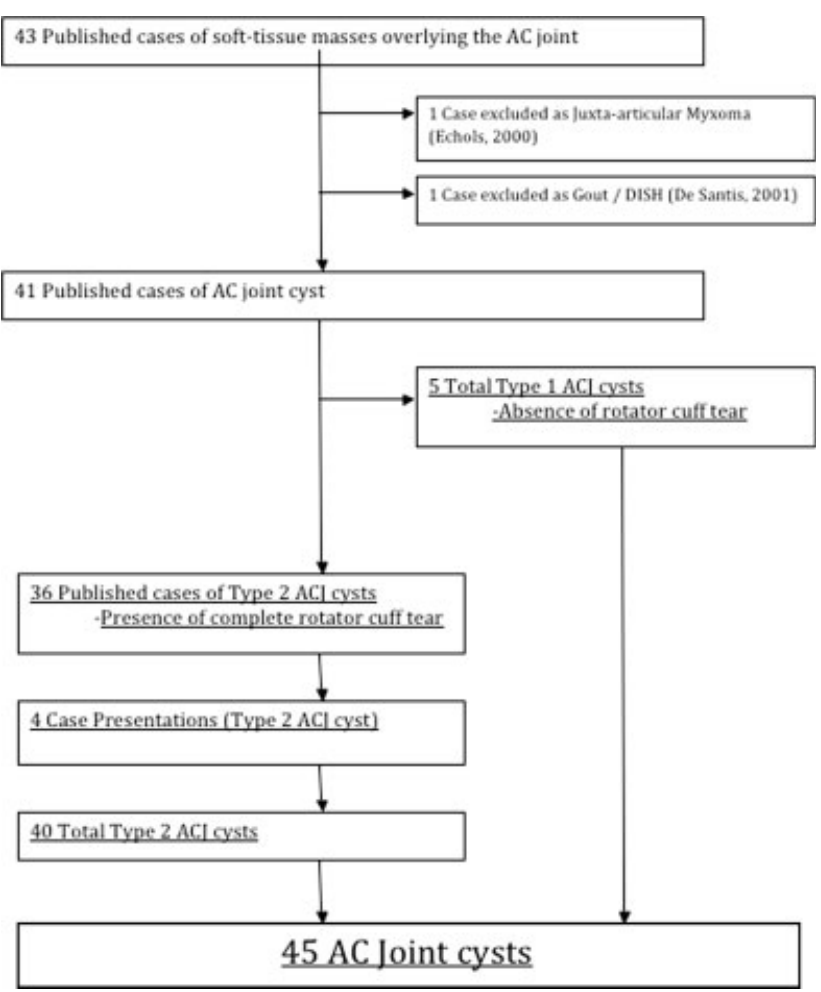

Fig. 1. Summary of article selection process.

the ACJ. The Type 2 cyst is dependant on the complete tear/rupture of the rotator cuff musculatureprincipally the avulsion of the supraspinatus tendon/ muscle. Overtime, a complete avulsion of the supraspinatus muscle allows for the superior migration of the humeral head leading to irritation and deterioration of the inferior acromioclavicular (AC) capsule. This can be confirmed on various imaging modalities, specifically X-ray, CT, and MRI. This condition is commonly referred to as cuff tear arthropathy (CTA) (Neer et al., 1983). The disruption of the congruity of the $\mathrm{GH}$ joint results in an increase in synovial fluid production and, subsequently, permits a direct column of fluid to flow from the $\mathrm{GH}$ joint into the $\mathrm{ACJ}$, referred to by Craig as a "geyser sign" (Craig, 1984). Diagnosis of the underlying pathology (i.e., massive rotator cuff tear) is essential for effective treatment of the ACJ cyst.

Several other possible etiologies exist for noncystic soft-tissue masses of the shoulder including ganglia, tumor, degenerative joint disease, rheumatoid arthritis, infection, juxta-articular myxoma, gout, ochronosis, diffuse idiopathic skeletal hyperostosis, synovial chondromatosis, avascular necrosis, and neuroarthropathy.

\section{METHODS}

Several aspects pertaining to the exact etiology and pathogenesis of ACJ cysts are still disputed in the scientific literature. The majority of the literature concerning $\mathrm{ACJ}$ cysts consists of individual case studies with no definitive literature review. In this study, we have performed a comprehensive review, exclusive to English language journals, of the literature regarding cyst pathogenesis. Previous attempts at compiling a complete record of all reported cases have combined several distinct conditions into a single category. It is the position of this author that several possible etiologies exist for cystic soft-tissue masses overlying the ACJ, and they must be differentiated for appropriate classification. In addition to the literature review, we present four case studies that further illustrate the proposed classification. Finally, this article presents treatment options that address the underlying pathology specific to each type of ACJ cyst.

\section{RESULTS}

The current review of the literature in this article presents a total of 45 cases of ACJ cysts (41 previously published reports plus four new case presentations) (Tables 1 and 2). Of the previously reported cases, five presented in the absence of a complete rotator cuff tear (Burns and Zvirbulis, 1984; Nardini, 1991; Segmuller et al., 1997; Kontakis et al., 2007). For the Type 1 cyst (occurring in the absence of a rotator cuff tear), the average age was $64.3( \pm 2.3)$ year, and cysts occurred in males $67 \%$ (2/3 cases) of the time. Three of these cases had confirmation of an intact rotator cuff by MRI, ultrasound, or arthroscopy (Burns and Zvirbulis, 1984; Segmuller et al.,

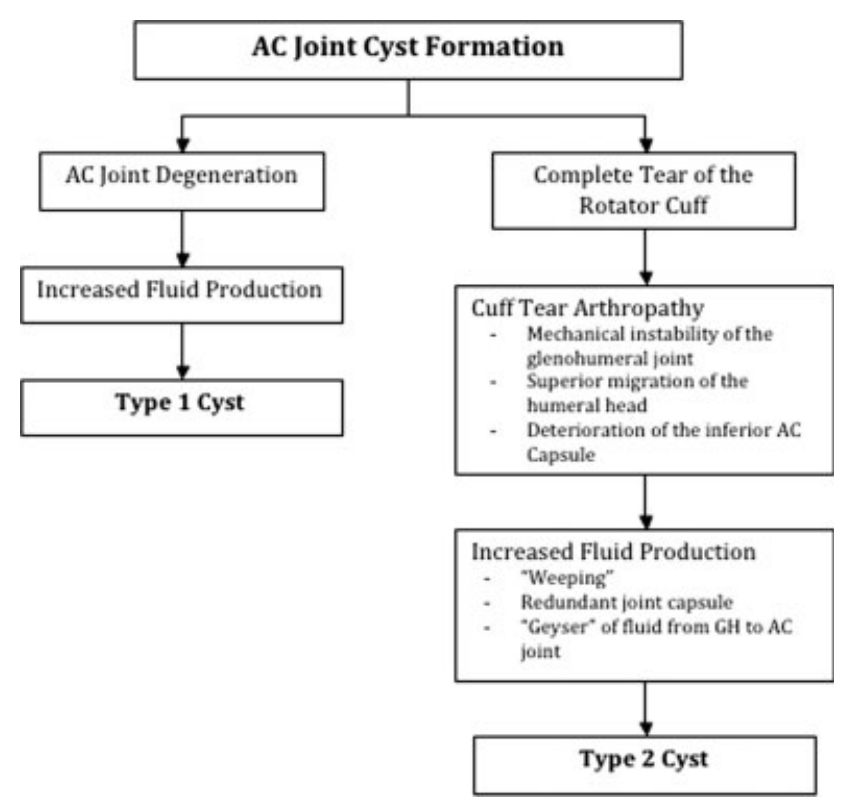

Fig. 2. Anatomic pathophysiology of ACJ cyst formation. ACJ degeneration has been documented in acute, chronic, and acute-on-chronic conditions. Complete rotator cuff tear can be identified in an acute stage, whereas CTA has been relegated to a chronic stage of joint degeneration and rotator cuff pathology. 
TABLE 1. Summary of Reported Type 2 AC Joint Cyst Cases

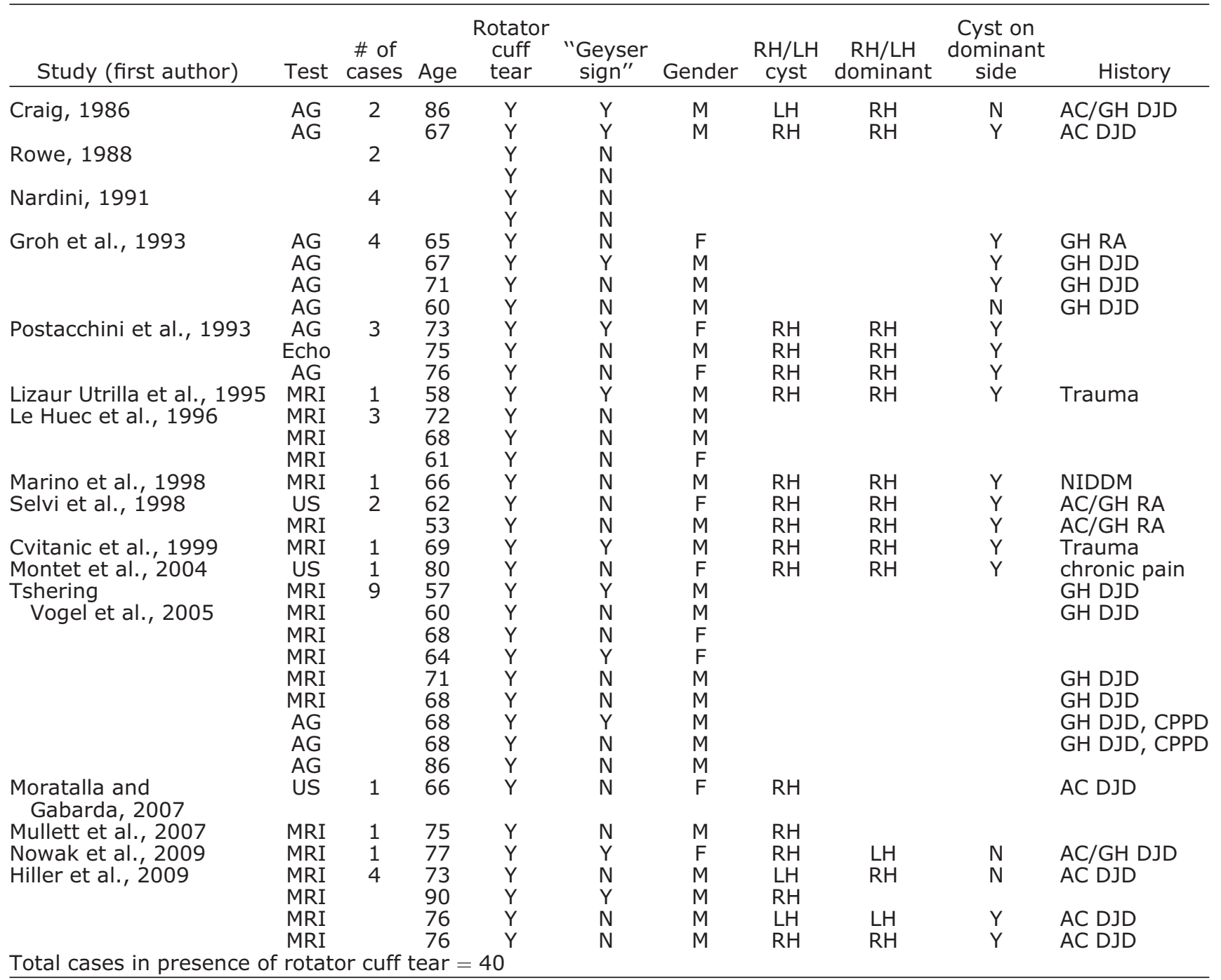

Test refers to diagnostic imaging, AC, acromioclavicular; AG, arthrogram; CPPO, calcium pyrophosphate dehydrade deposition diseases; DJD, degenerative joint diseases; $\mathrm{GH}$, glenohumeral; RA, rheumatoid arthritis; MRI, magnetic resonance imaging; NIDDM, noninsulin-dependant diabetes mellitus; US, ultrasound.

1997; Kontakis et al., 2007). The remaining two cases established continuity of the rotator cuff by $\mathrm{X}$-ray and physical exam (no pain on full range of motion). Surgical excision confirmed the original diagnosis (Nardini, 1991). One case of Type 1 cyst occurred with a concomitant history of noninsulindependant diabetes mellitus (NIDDM)(Segmuller et al., 1997). Thirty-six previously reported cases

TABLE 2. Summary of Reported Type 1 AC Joint Cyst Cases

\begin{tabular}{|c|c|c|c|c|c|c|c|c|c|}
\hline Author & $\begin{array}{l}\text { \# of } \\
\text { Cases }\end{array}$ & Age & $\begin{array}{c}\text { Rotator } \\
\text { cuff } \\
\text { tear }\end{array}$ & $\begin{array}{l}\text { "Geyser } \\
\text { sign" }\end{array}$ & Gender & $\begin{array}{c}\mathrm{RH} / \mathrm{LH} \\
\text { cyst }\end{array}$ & $\begin{array}{c}\mathrm{RH} / \mathrm{LH} \\
\text { dominant }\end{array}$ & $\begin{array}{l}\text { Cyst } \\
\text { dominant } \\
\text { side }\end{array}$ & History \\
\hline $\begin{array}{l}\text { Burns and Zvirbulis, } 1984 \\
\text { Nardini, } 1991\end{array}$ & $\begin{array}{l}1 \\
2\end{array}$ & 63 & $\begin{array}{l}\mathrm{N} \\
\mathrm{N} \\
\mathrm{N}\end{array}$ & $\begin{array}{l}N \\
N \\
N\end{array}$ & $F$ & & & & \\
\hline $\begin{array}{l}\text { Segmüller et al., } 1997 \\
\text { Kontakis et al., } 2007 \\
\text { Total cases in absence of } r\end{array}$ & $\begin{array}{c}1 \\
1 \\
\text { tor c }\end{array}$ & $\begin{array}{l}63 \\
67 \\
\text { tear }\end{array}$ & $5^{N}$ & $\begin{array}{l}\mathrm{N} \\
\mathrm{N}\end{array}$ & $\begin{array}{l}M \\
M\end{array}$ & $\begin{array}{l}\mathrm{LH} \\
\mathrm{RH}\end{array}$ & & & NIDDM \\
\hline
\end{tabular}

NIDDM, noninsulin-dependant diabetes mellitus. 


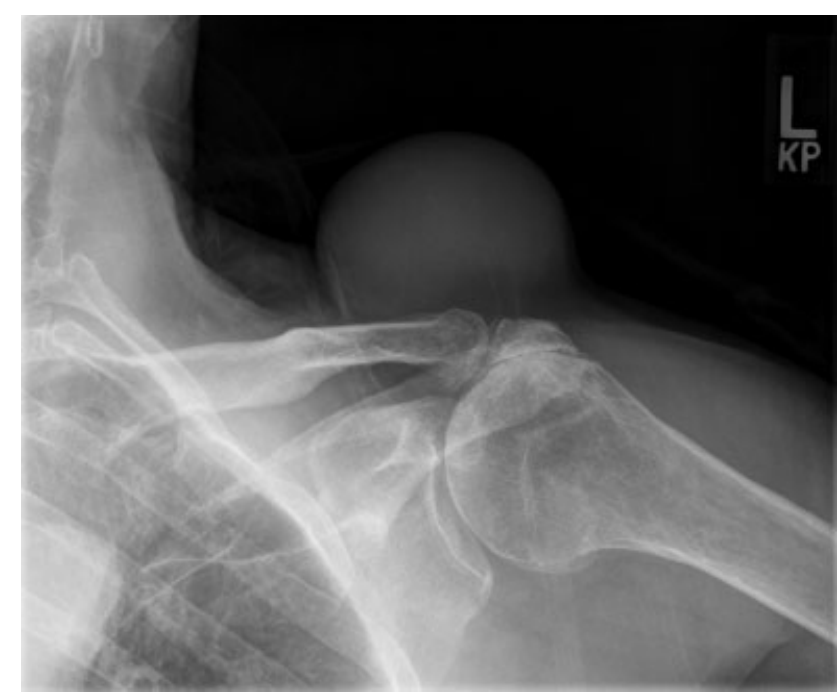

Fig. 3. AP X-ray of left shoulder joint demonstrating uncalcified mass and significant impingement.

occurred in individuals with complete tears of the rotator cuff (Craig, 1986; Rowe, 1988; Nardini, 1991; Groh et al., 1993; Postacchini et al., 1993; Lizaur Utrilla et al., 1995; Le Huec, 1996; Marino et al., 1998; Selvi et al., 1998; Cvitanic et al., 1999; Montet et al., 2004; Tshering Vogel et al., 2005; Moratella and Gabarda, 2007; Mullett et al., 2007; Nowak et al., 2009). For the Type 2 cyst (occurring in the presence of a complete rotator cuff tear), the average age was $68.5( \pm 7.8)$ year. Type 2 cysts occurred in males $67 \%$ (20/30 cases) of the time and occurred on the dominant-handed side $81 \%$ (13/16 cases) of the time. Concomitant medical histories for patients with a Type 2 cyst included nine cases with degenerative joint disease (DJD) of the $\mathrm{GH}$ joint, two cases with DJD of the $A C$ and $G H$ joints, two cases with DJD of the ACJ, two cases with rheumatoid arthritis (RA) of the $A C$ and $\mathrm{GH}$ joint, one case with RA of the $\mathrm{GH}$ joint, two cases with prior trauma, two cases with CPPD deposition disease, one case with chronic pain, and one case with NIDDM.

As a complement to the literature review, we report four additional case studies. The first, W.W., is a right-hand dominant (RHD) 73 year-old-male with a 7 month history of a painless $10 \times 6 \mathrm{~cm}$ mass over the left $A C J$. Patient had a history of AC, DJD, and CTA but no pain or shoulder dysfunction (Fig. 3). Treatment included aspiration of the cyst.

The second case, R.P., is a 90 year-old-male with a large right ACJ cyst preceded by a full-thickness rotator cuff tear (Figs. 4 and 5). MRI demonstrates a large cystic lesion overlying the ACJ with a wellformed "stalk" communicating between the $\mathrm{GH}$ and $\mathrm{ACJs}$ (Fig. 6). The MRI likewise demonstrates a cranial displacement of the humeral head because of a complete avulsion of the right rotator cuff musculature, enlargement of the shoulder joint capsule, and a pathological increase in the volume of intra- articular joint fluid. Upon histological sectioning, the cyst was found to communicate with the subacromial bursa and displayed the standard pathology of a fluid filled cavity with a simple synovial lining. Treatment included AC] resection, subacromial bursectomy, resection of the rotator cuff, and reformation of the shoulder joint capsule.

The third case, H.L., is a left-hand dominant 76 year-old-male with a 1 year history of a painful $8 \times 7 \mathrm{~cm}$ mass over the left ACJ. Patient had a failed left rotator cuff repair 10 year previously and a history of left AC DJD and CTA. Multiple cyst aspirations and steroid injections into the subacromial space failed to resolve the cyst. Treatment included cyst excision, distal clavicle excision (DCE), and arthroscopic debridement.

The fourth case, C.W., is a RHD 76 year-old-male with chronic $A C J$ pain and a cyst overlying the right $A C J$. Patient had a history of right rotator cuff repair 25 years previously, right AC DJD and CTA. Treatment included cyst excision, DCE, and hemiarthroplasty.

\section{DISCUSSION}

Two distinct etiologies exist for a cyst overlying the $A C J$ (Fig. 2). In the presence of an intact rotator cuff, an ACJ cyst can form superficially and be limited only to the ACJ. This type of cyst, Type 1 , has no fluid communication with the $\mathrm{GH}$ joint. The pathogenesis of the Type $1 \mathrm{ACJ}$ cyst is dependant on degenerative changes of the $\mathrm{ACJ}$ due to trauma (including dislocation), infection, metabolic disease, or repetitive overuse (Nardini, 1991; Kontakis et al., 2007). Overtime, degenerative changes of the ACJ can cause irritation of the synovium leading to an overproduction of fluid resulting in cyst formation superficial to the joint.

Alternatively, following a massive tear of the rotator cuff, another distinct condition can occur. A massive rotator cuff tear can lead to CTA, a disease with clearly discernible morphologic characteristics including increased production of intra-articular synovial fluid and the upward displacement of the humeral head, which in time can erode the ACJ and permit a geyser of fluid to flow from the $\mathrm{GH}$ joint into the ACJ. This type of cyst, Type 2, is dependant on a complete rotator cuff tear accompanied by subsequent degenerative changes of both the $\mathrm{GH}$ and ACJs.

By differentiating ACJ cysts into distinct categories, treatment options can be directed at the appropriate underlying pathology (Figs. 7 and 8). Treatment for the Type $1 \mathrm{ACJ}$ cyst can include resection of the distal clavicle and subacromial bursectomy (Kontakis et al., 2007). Treatment for the Type 2 AC] cyst remains a topic of controversy. Treatment options for the underlying CTA include resection of the distal clavicle, arthroscopic irrigation and debridement, ACJ arthrodesis, total shoulder arthroplasty, hemiarthroplasty, and reverse total shoulder arthroplasty (Feeley et al., 2009). Although the underlying rotator cuff pathology must be addressed, repair is not always possible due to the extent of the cuff tear. Concomitant conditions and functional 


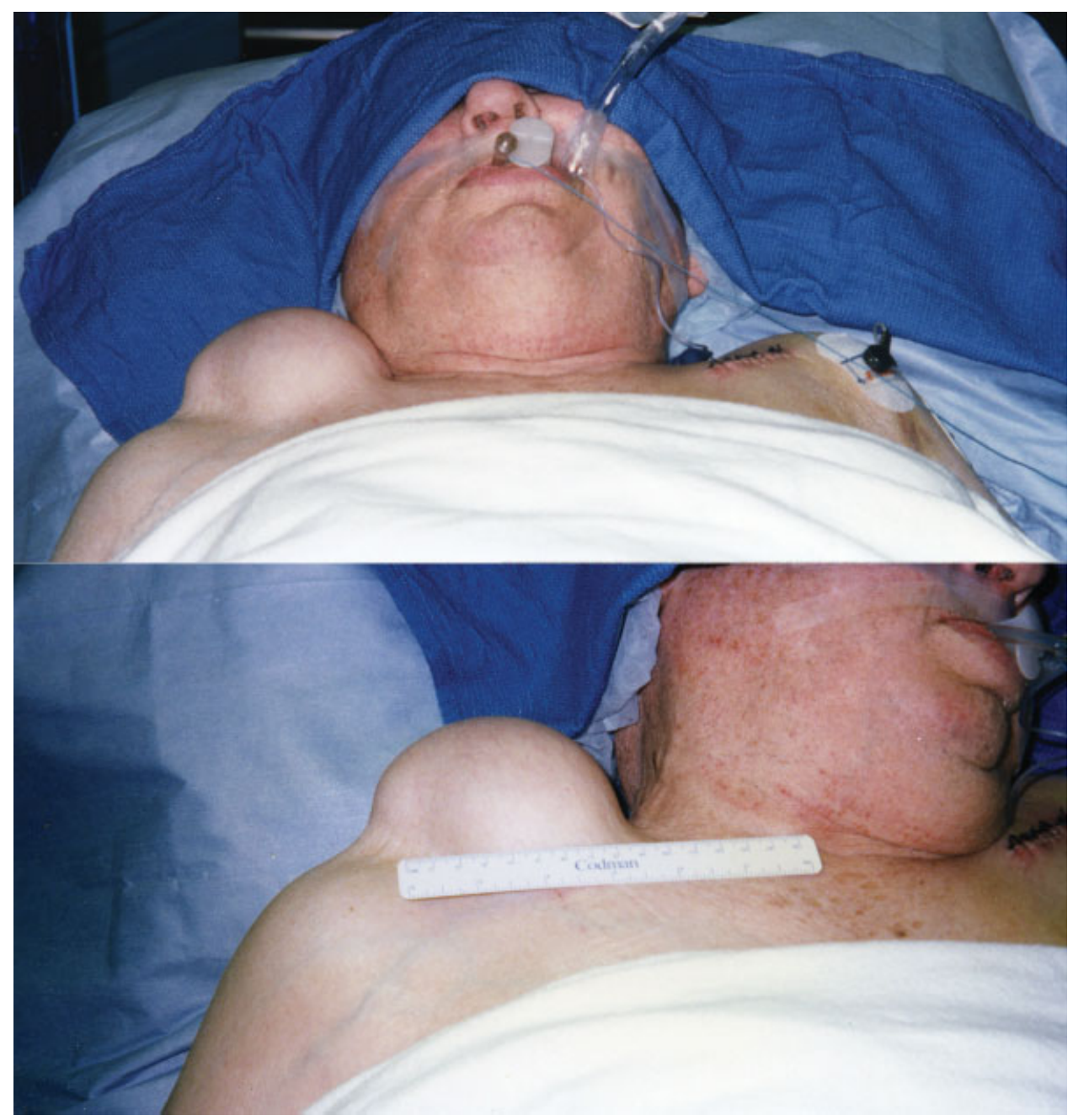

Fig. 4. Preoperative photographs demonstrating large right type $2 \mathrm{ACJ}$ cyst.

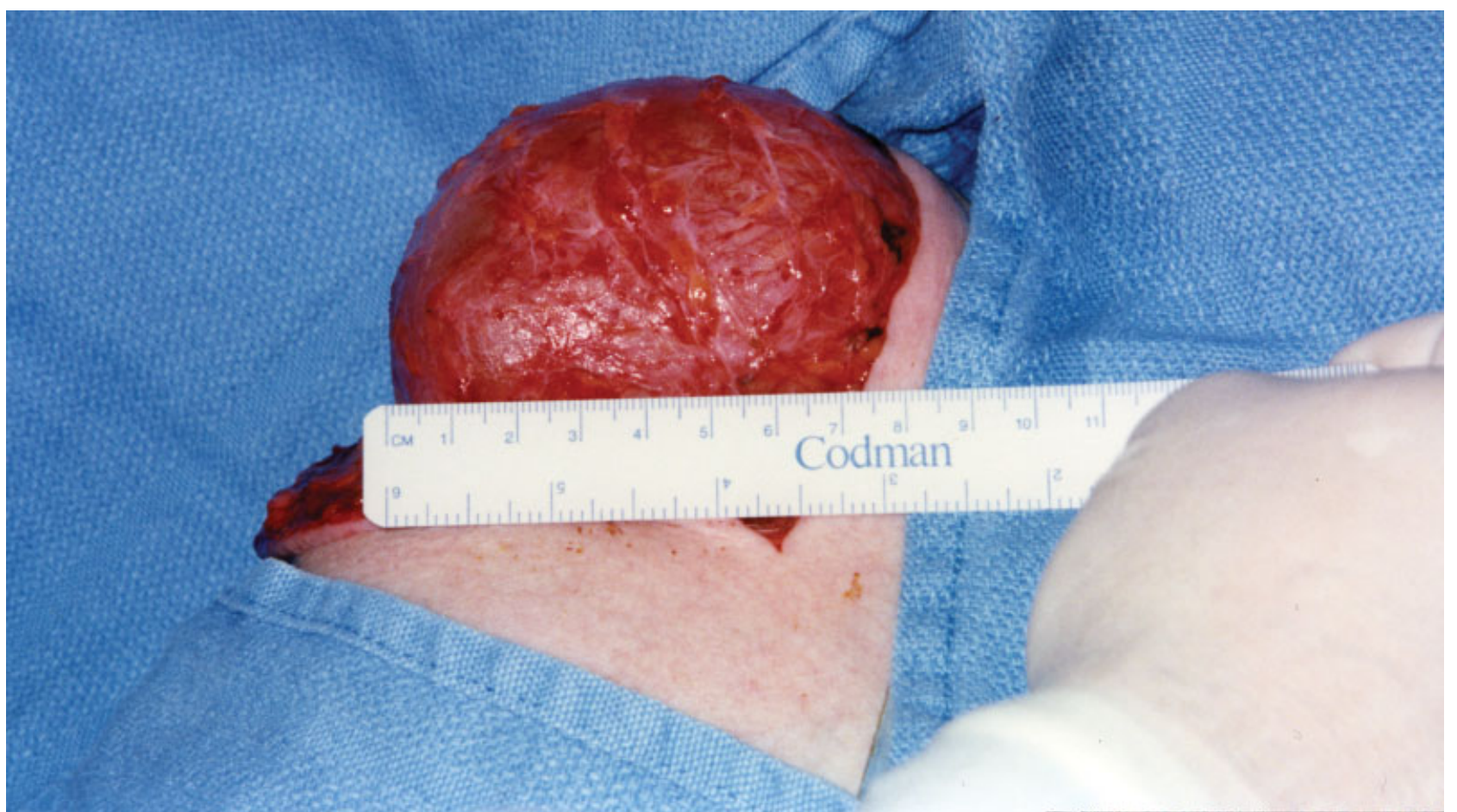

Fig. 5. Intraoperative photograph demonstrating $10 \times 8 \mathrm{~cm}$ cystic mass. 


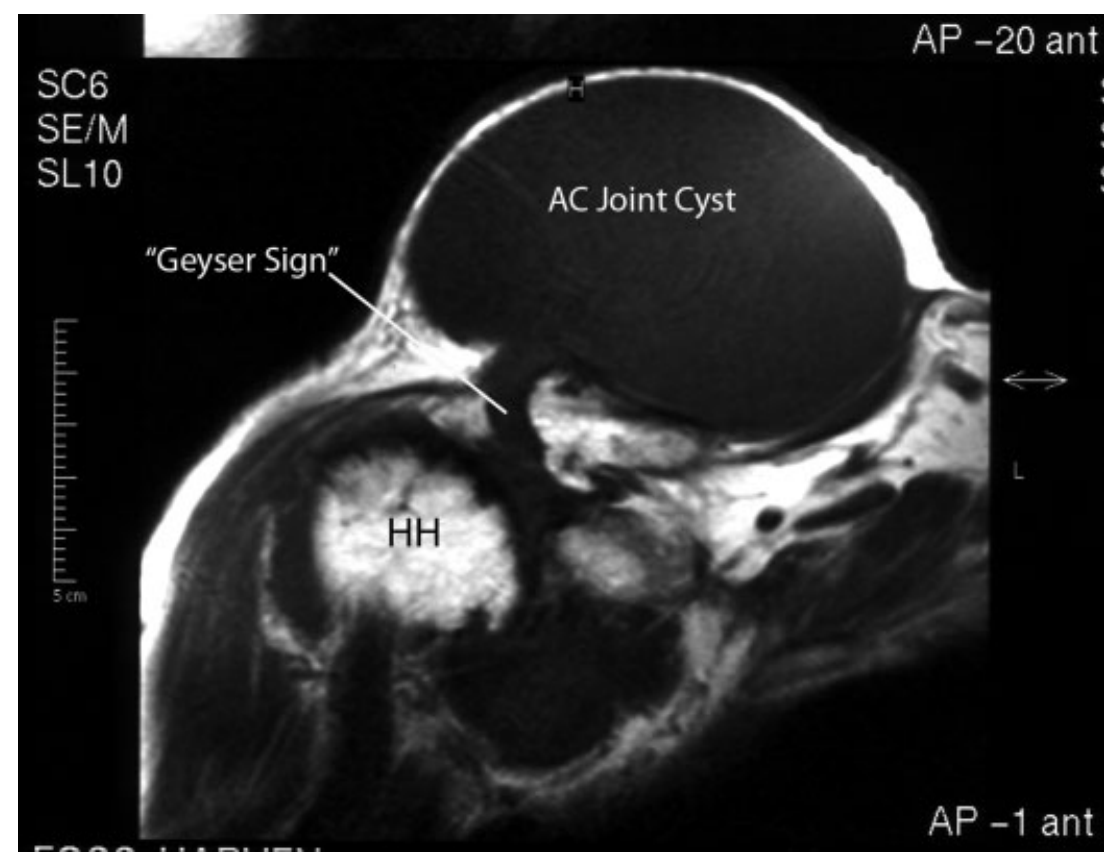

Fig. 6. T1-weighted coronal oblique MRI identifying degenerative changes of the humeral head, large cystic mass, "geyser sign," enlarged shoulder joint capsule, and a pathological increase in intra-articular fluid.

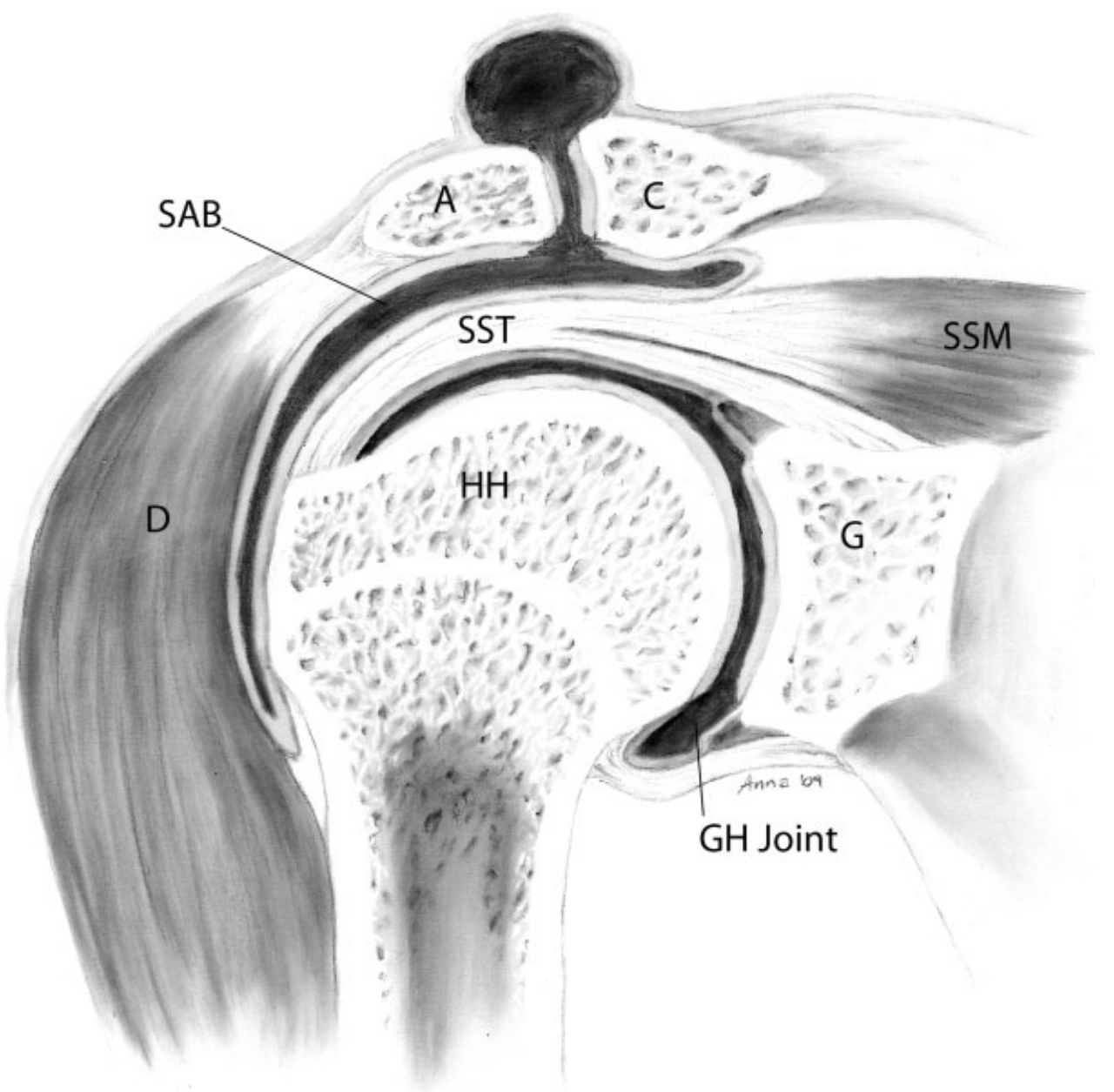

Fig. 7. Illustration of Type $1 \mathrm{ACJ}$ cyst: deterioration/disruption of $S A B$ and $A C J$, accumulation of synovial fluid, intact rotator cuff, ACJ cyst. A, acromion; C, clavicle; $\mathrm{D}$, deltoid muscle; G, glenoid; $\mathrm{GH}$ joint, glenohumeral joint; $\mathrm{HH}$, humeral head; SAB, subacromial bursa; SSM, supraspinatus muscle; SST, supraspinatus tendon. 


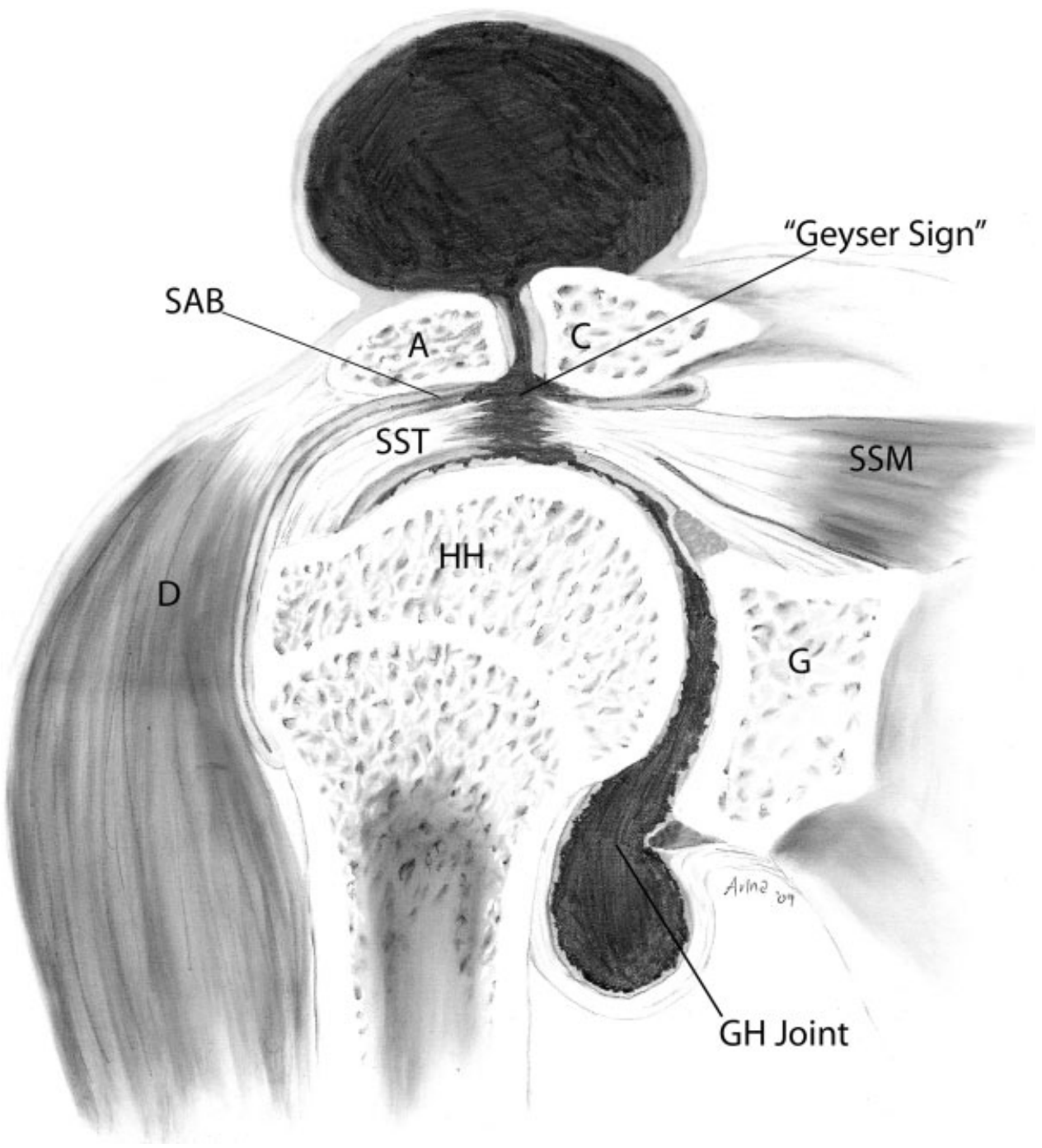

Fig. 8. Illustration of Type 2 ACJ cyst: complete tear of SST/SSM, instability of $\mathrm{GH}$ joint with superior migration of $\mathrm{HH}$, accumulation of synovial fluid, "geyser sign," ACJ cyst. A, acromion; C, clavicle; D, deltoid

deficiencies determine the appropriate treatment paradigm. Current treatment guidelines (Feeley et al., 2009) include resection of the distal clavicle and also:

1. Shoulder arthrodesis: patients with significant anterior deltoid deficiency or multiple previous surgeries.

2. Arthroscopy and debridement: high-risk patients with multiple medical comorbidities.

3. Total shoulder arthroplasty: patients with a repairable rotator cuff.

4. Hemiarthroplasty: patients with an intact deltoid, intact coracoacromial ligament, forward flexion $>90^{\circ}$, and external rotation $>30^{\circ}$.

5. Reverse total shoulder arthroplasty: patients with an intact deltoid and incompetent cora- muscle; G, glenoid; $\mathrm{GH}$ joint, glenohumeral joint; $\mathrm{HH}$, humeral head; SAB, subacromial bursa; SSM, supraspinatus muscle; SST, supraspinatus tendon.

coacromial ligament, particularly elderly patients with low demand.

\section{REFERENCES}

Burns J, Zvirbulis R. 1984. A ganglion arising over the acromioclavicular joint: A case report. Orthopedics 7:1002-1004.

Craig EV. 1984. The geyser sign and torn rotator cuff: Clinical significance and pathomechanics. Clin Orthop Relat Res 191:213-215.

Craig EV. 1986. The acromioclavicular joint cyst: An unusual presentation of a rotator cuff tear. Clin Orthop Relat Res 202: $189-192$.

Cvitanic O, Schimandle J, Cruse A, Minter J. 1999. The acromioclavicular joint cyst: Glenohumeral joint communication revealed by MR arthrography. J Comput Assist Tomogr 23:141-143.

De Santis D, Palazzi C, D'Amico E, Di Mascio DE, Pace-Palitti V, Petricca A. 2001. Acromioclavicular cyst and 'porcupine shoulder' in gout. Rheumatology 11:1320-1321. 
Echols PG, Omer GE Jr, Crawford MK. 2000. Juxta-articular myxoma of the shoulder presenting as a cyst of the acromioclavicular joint: A case report. J Shoulder Elbow Surg 9:157-159.

Feeley BT, Gallo RA, Craig EV. 2009. Cuff tear arthropathy: Current trends in diagnosis and surgical management. J Shoulder Elbow Surg 18:484-494.

Groh G, Badwey T, Rockwood CA Jr. 1993. Treatment of cysts of the acromioclavicular joint with shoulder hemiarthroplasty. J Bone Joint Surg Am 75:1790-1794.

Hiller et al. 2009. "Acromioclavicular joint cyst formation." Poster presentation. SBRP Research Forum. Ann Arbor, Michigan. 5 November 2009.

Kontakis GM, Tosounidis TH, Karantanas A. 2007. Isolated synovial cyst of the acromio-clavicular joint associated with joint degeneration and an intact rotator cuff. Acta Orthop Belg 73:515520.

Le Huec JC, Zipoli B, Schaeverbeke T, Moinard M, Chauveaux D, Le Rebeller A. 1996. Acromio-clavicular joint cyst. Surgical treatment. Acta Orthop Belg 62:107-112.

Lizaur Utrilla A, Marco Gomez L, Perez Aznar A, Cebrian Gomez R. 1995. Rotator cuff tear and acromioclavicular joint cyst. Acta Orthop Belg 61:144-146.

Marino AJ, Tyrrell PN, El-Houdiri YA, Kelly CP. 1998. Acromioclavicular joint cyst and rotator cuff tear. J Shoulder Elbow Surg 7: 435-437.

Montet X, Zamorani-Bianchi MP, Mehdizade A, Martinoli C, Bianchi S. 2004. Intramuscular ganglion arising from the acromioclavicular joint. Clin Imaging 28:109-112.
Moratalla MB, Gabarda RF. 2007. Acromioclavicular joint ganglion. Eur J Radiol Extra 63:21-23.

Mullett H, Benson R, Levy O. 2007. Arthroscopic treatment of a massive acromioclavicular joint cyst. Arthroscopy 23:446.e1446.e4.

Nardini C. 1991. Sul significato delle cisti acromio-clavicolari. Loro associazone con la rottura della cuffia dei rotatori. Minerva Orthop 42:211-216.

Neer CS II, Craig EV, Fukuda H. 1983. Cuff-tear arthropathy. J Bone Joint Surg Am 65:1232-1244.

Nowak DD, Covey AS, Grant RT, Bigliani LU. 2009. Massive acromioclavicular joint cyst. J Shoulder Elbow Surg 18:e12-e14.

Postacchini F, Perugia D, Gumina S. 1993. Acromioclavicular joint cyst associated with rotator cuff tear: A report of three cases. Clin Orthop Relat Res 294:111-113.

Rockwood C, Burkhead WZ. 1988. Management of patients with massive rotator cuff defects by acromioplasty and rotator cuff debridement. Orthop Trans 12:190-193.

Rowe CR. 1988. Symptomatic Cysts of the Acromioclavicular Joint. The Shoulder. New York: Churchill Livingstone. p 644-645.

Segmüller HE, Saies AD, Hayes MG. 1997. Ganglion of the acromioclavicular joint. J Shoulder Elbow Surg 6:410-412.

Selvi E, De Stefano R, Frati E, Manganelli S, Manca S, Marcolongo R. 1998. Rotator cuff tear associated with an acromioclavicular cyst in rheumatoid arthritis. Clin Rheumatol 17:170-171.

Tshering Vogel DW, Steinbach LS, Hertel R, Bernhard J, Stauffer E, Anderson SE. 2005. Acromioclavicular joint cyst: Nine cases of a pseudotumor of the shoulder. Skeletal Radiol 34:260-265. 